\title{
Addressing the triple burden of malnutrition in the time of COVID-19 and climate change in Small Island Developing States: what role for improved local food production?
}

\author{
Gordon M. Hickey ${ }^{1}$ (D) Nigel Unwin ${ }^{2,3,4}$ (D) \\ Received: 21 May 2020 / Accepted: 30 June 2020 / Published online: 9 July 2020 \\ (C) International Society for Plant Pathology and Springer Nature B.V. 2020
}

\begin{abstract}
The impacts of the COVID-19 pandemic on food and nutrition insecurity are likely to be significant for Small Island Developing States due to their high dependence on foreign tourism, reliance on imported foods and underdeveloped local food production systems. SIDS are already experiencing high rates of nutrition-related death and disability, including double and triple burdens of malnutrition due to unhealthy diets. We consider the potential role for improved local food production to offset the severity of food system shocks in SIDS and identify the need for localized approaches to embrace systems thinking in order to facilitate communication, coordination and build resilience.
\end{abstract}

Keywords Food systems $\cdot$ Decentralization $\cdot$ Food sovereignty $\cdot$ Collective action $\cdot$ Complexity $\cdot$ Transitions

An unanticipated chain of events has caused international supply chains to collapse, further isolating this Caribbean island state. Land previously used for export crops, primarily sugarcane, lie idle. Food imports dry up, food prices spike and access to oil and other agricultural inputs become severely restricted. Industrialized agricultural production is no longer viable, with dramatic implications for local food production, variety and availability, causing a severe food shock. Average calorie consumption drops by up to a third. A revolution in the design of the domestic food system necessitates a drastic social change towards vegetable diets based on seasonally available produce. Government rations supply the staple foods of most households, with millions of people in cities relying on community gardens

Gordon M. Hickey

gordon.hickey@mcgill.ca

Nigel Unwin

nigel.unwin@mrc-epid.cam.ac.uk

1 Department of Natural Resource Sciences, Faculty of Agricultural and Environmental Sciences, McGill University, Montreal, Canada

2 MRC Epidemiology Unit, University of Cambridge, Cambridge, UK

3 European Centre for Environment and Human Health, University of Exeter Medical School, Devon, UK

4 George Alleyne Chronic Disease Research Centre, University of the West Indies, Wanstead, Barbados and the hundreds of urban farms that have been established on unused areas of land to grow their fruit and vegetables. Operating through cooperative and community-supported models of organization, these urban farms have enabled local communities to take greater responsibility for meeting their food needs while also offering them employment opportunities. Agroecological practices, many of which are labour intensive, are relied upon across the country to maximize production and energy efficiency, also offering employment in the rural communities previously dependent on export commodity production systems. Most of the national demand for fresh fruit and vegetables is now produced domestically. The forced public policy drive towards self-sufficiency has required considerable hardship and sacrifice, including undesired dietary and lifestyle changes. Nevertheless, the transformation has had the benefits of increasing household food and nutrition security and community resilience to external shocks, and shifting the diet towards one with a lower risk of non-communicable diseases.

The situation described above is broadly based on the food system crisis that occurred in the Small Island Developing State (SIDS) of Cuba between 1989 and 1993 due to a sudden shortage of imported oil, food and agricultural inputs combined with a collapse in domestic export industries caused by the demise of the Soviet Bloc (Altieri et al. 1999; Garth 2009; Wright 2012). While the political and economic systems operating in Cuba differ in important ways from those that operate in other Small Island Developing States (SIDS) 
around the world today, their food system responses to a significant external shock are instructive. There are 58 countries and territories formally classified as 'SIDS' by the United Nations (UN), of which 38 are full members of the UN, with the majority situated in the Caribbean and Pacific (Fig. 1). These small island nations share some special challenges, such as high vulnerability to external economic shocks, economies that are heavily reliant on tourism and are deeply integrated into global markets, limited resources (human, financial and natural), generally high communication, energy and transportation costs, and increasing susceptibility to natural disasters caused by climate change (Food and Agriculture Organization (FAO) et al. 2017; Connell et al. 2020).

Most SIDS are highly dependent on food imports, a feature that has increased markedly over the past three decades. For example, since 1990, the proportion of food consumed that is imported has risen from around $40 \%$, to over $60 \%$ for SIDS in the Caribbean and Pacific, with half of them importing over $80 \%$ of their food. The top 5 food imports are highly or ultra-processed foods, wheat, corn, meat and diary. On average SIDS in the Caribbean and Pacific spend $20 \%$ of what they earn from all exports on food imports, compared to a global average of 5\%. However, for many
SIDS the proportion spent on food imports is much higher, e.g. $48 \%$ in Jamaica, $49 \%$ in Barbados, $67 \%$ in St Kitts and Nevis, and $103 \%$ in Dominica (http://data.un.org/). Many SIDS also experience high rates of nutrition-related death and disability (GBD Diet Collaborators 2019), including double and triple burdens of malnutrition (Global Nutrition Report 2020), i.e. co-existing overweight and obesity, childhood underweight and stunting, and micronutrient deficiencies (especially iron deficiency in women).

Food and nutrition security in SIDS has therefore been identified as an international policy priority (United Nations (UN) 2014; FAO et al. 2017). The 2017 Global Action Programme (GAP) on Food Security and Nutrition in Small Island Developing States seeks to achieve sustainable food security through three mutually reinforcing objectives: strengthening enabling environments; improving sustainability, resilience and nutrition sensitivity of local food systems; and empowering people and communities (FAO et al. 2017). Building on this framework, we consider how the COVID-19 pandemic might shock domestic food systems in SIDS and prompt affected governments and communities towards new models and approaches aimed at enhancing local food production.

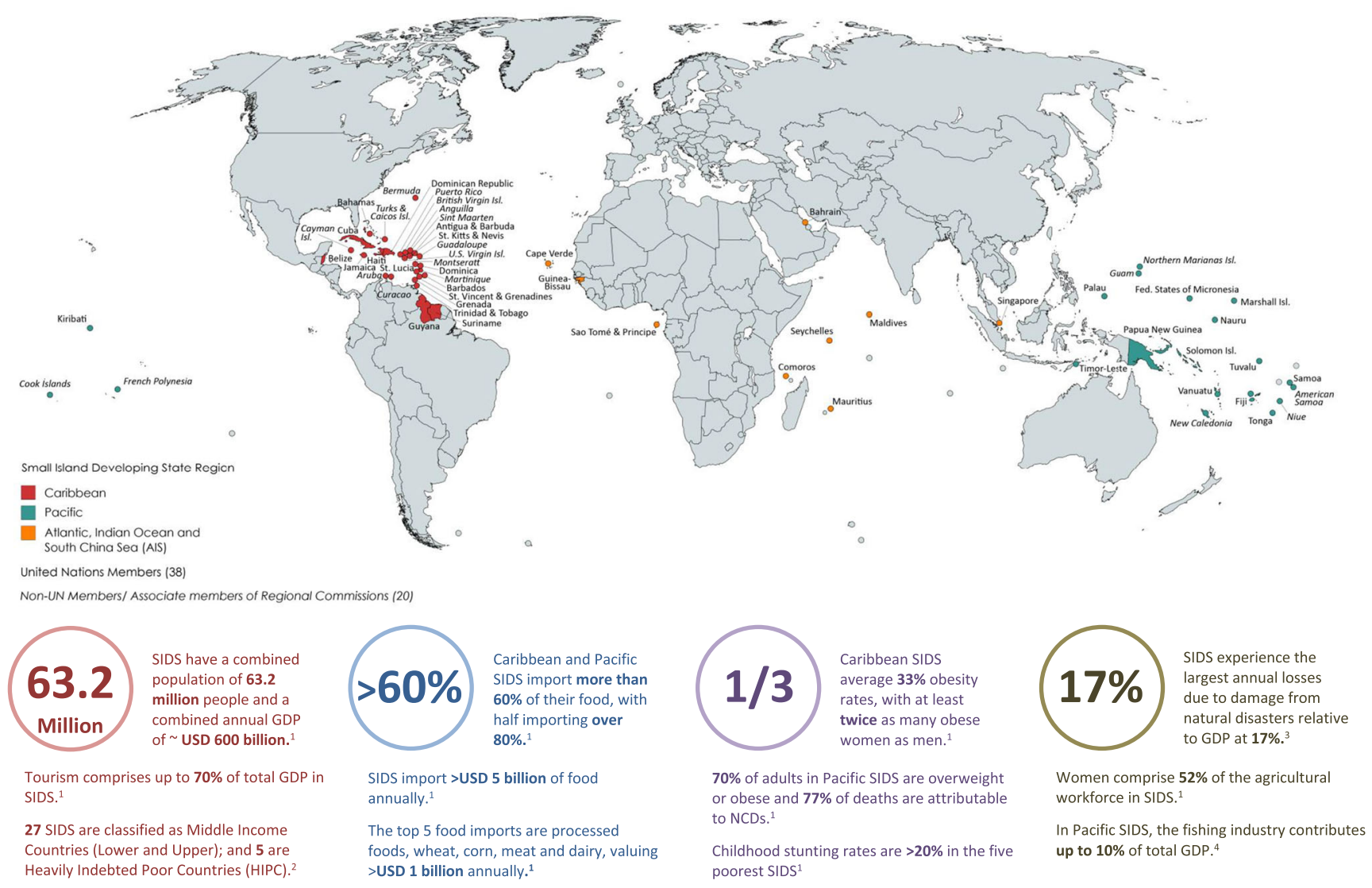

Fig. 1 World map showing the 58 Small Island Developing States (SIDS), with key facts and figures for the 38 United Nations Member States. Map created with mapchart.net. Data sources: FAO 2019²; World Bank $2020^{2}$; OECD 2018 ; UN-OHRLLS $2015^{4}$ 


\section{COVID-19 pandemic, climate change and food security in Small Island developing states}

As noted by Ruben et al. (2020), the COVID-19 pandemic is putting significant pressure on food and health systems internationally, highlighting "the need to fundamentally reshape their organization" in order to reduce the potential negative impacts on poverty, nutrition and hunger. In the case of many SIDS, these pressures are likely to be particularly significant due to their high dependence on food imports, limited or nonexistent food storage infrastructure, high rates of poverty and high burdens of chronic, non-communicable diseases (NCDs) associated with unhealthy diets (FAO 2016). In the SIDS of the Caribbean Community (CARICOM), where $80 \%$ of food is imported [primarily from the USA $(47.25 \%)$, the Netherlands (4.85\%) and the United Kingdom (3.50\%)], a recent (April, 2020) web-based survey, with four and half thousand respondents from 19 countries and territories, investigated the impact of COVID-19 on food security and livelihoods. The survey identified widespread disruption to livelihoods, including some difficulty accessing markets and purchasing desired food, hygiene products and medicines, altered food shopping behaviours and some people reporting the need to eat less-preferred foods (World Food Programme 2020). While the impacts of the COVID-19 pandemic on CARICOM food systems are only just starting to be felt within local communities, these early indications of household food stress will raise concerns for national governments. The authors of the report, which include both the WFP and the FAO, go on to state that governments in the region should "galvanise local production to meet future demands and ensure trade supply chains remain open". Such a recommendation repeats previous food security directions, including the Jagdeo Initiative (2004), the subsequent Regional Food and Nutrition Security Policy (2011), formally endorsed but largely unimplemented, the commitments made by governments of all SIDS in the SAMOA pathway (UN 2014) and subsequent GAP (FAO et al. 2017). There is no shortage of policy commitments and guidance. The formidable task now is to act rapidly on these commitments while facing a severe economic downturn due to the COVID-19 pandemic.

The economies of most SIDS are highly dependent on tourism, accounting for $\sim 30 \%$ of GDP in SIDS on average, and up to $66 \%$ in some nations (Coke-Hamilton 2020). A recent report by the UN World Tourism Organization (April, 2020) identified SIDS as being the most vulnerable to the "sudden, deep and likely prolonged downturn in the travel and tourism sectors" and that the magnitude of the shock is likely to be greater than a $30 \%$ contraction in earnings from tourism and potentially up to $80 \%$, lasting for 18 months or more (Coke-Hamilton 2020). The report goes on to warn that SIDS will have limited access to additional borrowing or foreign currency reserves due to being already "highly indebted and not well diversified", with many SIDS possessing reserves sufficient for only a few months worth of imports (Coke-Hamilton 2020). Yet, as already described, the proportion of export earnings required to service food imports for most SIDS was already high. A key question is how rapidly, and by how much, can the food import bill be reduced?

Of further relevance to food security, a 2016 FAO report estimated that in some SIDS, supermarkets and food distributors may have only four weeks of food supply on their shelves and in warehouses. More broadly, many SIDS have already been feeling the pressures created by climate change, such as increasing frequency and severity of tropical storms, intermittent droughts, acidification of oceans, and rising sea levels, which have negatively affected domestic food production and also the demand for tourism within affected nations (Connell et al. 2020). With the additional economic shock of the evolving COVID-19 pandemic likely to be significant in both magnitude and duration, the need for food system transformation in many SIDS is even more pressing, and will need to foster resilience against the potential effects of climate change.

\subsection{What role for improved local food production?}

Even before COVID-19 there was an urgent need to take action to ensure sustainable food security in SIDS. Decreasing reliance on food imports through increased local food production has a key role. How this is done must be informed by an understanding of how SIDS' food systems currently function. We are part of a project that engaged stakeholders from across the food chain in mapping the food systems of three Caribbean SIDS (Guariguata et al. 2020). The food system maps illustrate the complex interconnected nature of the system, and the need for coordinated, mutually reinforcing interventions. For example, successfully promoting increased local food production and consumption may require interventions to improve access to land, provision of cold chain storage facilities, marketing, challenging social preferences for imported foods, re-kindling knowledge and skills in the preparation of local foods, and so on.

Lessons on how to engage with local communities to improve food production and nutrition may be learnt from the Civil Society Organisations (CSOs) already working in this area. This is what the Innov4AgPacific project, which began in 2018, is aiming to do. It is working with 8 CSOs that have a track record, in 6 Pacific states, of engaging with communities to improve agriculture, health and nutrition (Iese et al. 2020). One CSO is the Foundation for Rural Integrated Enterprises and Development (FRIEND) in Fiji (http://friendfiji.com/), whose work aims to integrate social empowerment, sustainable livelihoods, and health. Backyard gardening projects, based on sustainable agriculture principles, is one 
approach taken by FRIEND. Their approach includes training community members in nutrition and food preparation, and in adding value to excess produce through preservation and processing. A contrasting CSO example from Innov4AgPacific is the Kastom Garden Association (KGA) in the Solomon Islands. This is a smallholder farmers' organisation, whose work includes support to produce high quality planting material, rapidly increasing cultivation of selected tropical root crops as local resilient alternatives to imported staples, and the preservation and sharing of seeds. With the right support and scale up CSOs like FRIEND and KGA could provide one approach to significantly improving local food production and consumption in SIDS.

Another approach that has been trialed in SIDS involves developing nutrition sensitive value chains that connect local farmers to consumers through institutional food procurement, processing and preparation systems. Such 'farm to fork', (alternatively 'farm to school' or 'farm to table') value chains aim to develop local agricultural production capacity while increasing the availability of nutrients in local diets (Lowitt et al. 2018). While the COVID-19 pandemic is likely to reduce private sector demand for local produce (e.g., from hotels, restaurants and resorts), leveraging existing public expenditure on the community feeding programs operating in schools, hospitals, prisons, daycares, nursing homes and other public institutions may offer an opportunity to increase the resilience and nutrition sensitivity of local food production systems. Lessons learned through a recent 'farm to fork' school feeding model piloted in the Caribbean SIDS of St Kitts \& Nevis and Trinidad \& Tobago by researchers from the University of the West Indies and McGill University working in partnership with the public agencies responsible for health, education and agriculture, suggests that such an approach can deliver benefits to local farmers while also increasing the consumption of fruits and vegetables by children (Lowitt et al. 2018). However, the approach was also found to be organizationally demanding, requiring considerable communication, coordination and cooperation across different community groups working along the value chain (Lowitt et al. 2015). With adequate community engagement and policy coordination across government agencies, a 'farm to fork'type approach could form part of a multifaceted local food systems response to the food and nutrition challenges facing SIDS (Lowitt et al. 2018).

\subsection{Moving forward and setting an applied research agenda}

A recent systematic scoping review found limited published evidence from SIDS on the social, economic, environmental and particularly the health impacts of local food production initiatives (Haynes et al. 2018). The urgent need for applied research to guide and evaluate the upscaling of local food production, consumption and food security in SIDS in response to COVID-19 was recently emphasized by Drs Fletcher-Paul and Hutchinson from the Faculty of Food and Agriculture, at the University of the West Indies (Faculty of Food and Agriculture 2020). Applied research needs to be framed within a food systems perspective, considering that the success of an intervention in one part of the food system will often be contingent on the success of interventions in other parts. As noted above, applied research could further investigate the different social organization and collective action models already operating in SIDS that aim to increase food production and improve nutrition. Such research would include understanding the levels of engagement among women, youth, seniors and those living in poverty and seek to inform workable strategies for enhancing community resilience and sustainable food security in the face of systemic shocks. Exploring new ways to share and significantly scale up successful approaches to increasing local food production and consumption in SIDS will be important. While we recognize that developing equitable local food systems within SIDS will not solve all of the potential food security challenges and hardships likely to arise in the event of a pandemic-related shock, collective efforts to trial and evaluate different local food system approaches at different scales will be an essential part of the response.

\section{Compliance with ethical standards}

Conflict of interest The authors declared that they have no conflict of interest.

\section{References}

Altieri, M. A., Companioni, N., Cañizares, K., Murphy, C., Rosset, P., Bourque, M., \& Nicholls, C. I. (1999). The greening of the "barrios": Urban agriculture for food security in Cuba. Agriculture and Human Values, 16(2), 131-140.

Coke-Hamilton, P. (2020). Impact of COVID-19 on tourism in small island developing states. UNCTAD. https://unctad.org/en/pages/ newsdetails.aspx? OriginalVersionID=2341 Accessed 2 May 2020.

Connell, J., Lowitt, K., Saint Ville, A. and Hickey G.M. (2020). Food security and sovereignty in Small Island developing states: Contemporary crises and challenges. In J. Connell \& K. Lowitt (Eds.), Food Security in Small Island States (pp. 1-23). Springer.

Faculty of Food and Agriculture. (2020). COVID-19: A wake up call for regional food and nutrition security [Internet]: uwitv; 2020 5th May Podcast. Available online: https://www.youtube.com/channel/ UCN-DinGRVq5fDxa4byT8XwQ/videos Accessed 8 May, 2020.

Food and Agriculture Organization of the United Nations (FAO) (2016). State of Food Security and Nutrition in Small Island Developing States (SIDS). http://www.fao.org/3/a-i5327e.pdf Accessed 2 May, 2020.

FAO (2019). FAO'S work with Small Island Developing States: Transforming food systems, sustaining small islands. http://www. fao.org/3/ca5170en/ca5170en.pdf Accessed 21 June 2020.

FAO, UN-OHRLLS, UN-DESA. (2017). Global action Programme on food security and nutrition in Small Island developing states. Rome: 
FAO. http://www.fao.org/policy-support/resources/resourcesdetails/en/c/1027540/ Accessed 8 May 2020.

Garth, H. (2009). Things became scarce: Food availability and accessibility in Santiago de Cuba then and now. Napa Bulletin, 32(1), 178192.

GBD Diet Collaborators. (2019). Health effects of dietary risks in 195 countries, 1990-2017: A systematic analysis for the global burden of disease study 2017. Lancet, 393(10184), 1958-1972.

Global Nutrition Report (2020). https://globalnutritionreport.org/ Accessed 8 May 2020.

Guariguata, L., Rouwette, E. A., Murphy, M. M., Saint Ville, A., Dunn, L. L., Hickey, G. M., Jones, W., Samuels, T. A., \& Unwin, N. (2020). Using group model building to describe the system driving unhealthy eating and identify intervention points: A participatory, stakeholder engagement approach in the Caribbean. Nutrients., 12(2).

Haynes, E., Brown, C., Wou, C., Vogliano, C., Guell, C., \& Unwin, N. (2018). The community food and health project. Health and other impacts of community food production in Small Island developing states: A systematic scoping review. Revista Panamericana de Salud Pública, 42, e176.

Iese, V., Wairiu, M., Fesaitu, J., Teva, C., Navunicagi, O., Unwin, N., Haynes, E., Guell, C. \& Francis, J. (2020). Technical brief: Building the evidence base on community food production initiatives in Pacific Island countries. Wageningen; 2020. Contract no.: 34.

Lowitt, K., Hickey, G. M., Ganpat, W., \& Phillip, L. (2015). Linking communities of practice with value chain development in smallholder farming systems. World Development, 74, 363-373.

Lowitt, K., Gray-Donald, K., Hickey, G. M., Saint Ville, A., Ganderson, I., Madramootoo, C., \& Phillip, L. (2018). The obesity pandemic \& food insecurity in developing countries: A case study from the Caribbean. In A. Karpyn (Ed.), Food and Public Health: A Practical Introduction (pp. 255-279). Oxford: Oxford University Press.

Office of the High Representative for the Least Developed Countries, Landlocked Developing Countries and Small Island Developing States (UN-OHRLLS). (2015). Small Island developing states in Numbers. https://sustainabledevelopment.un.org/content/ documents/2189SIDS-IN-NUMBERS-CLIMATE-CHANGEEDITION_2015.pdf Accessed 25 June 2020.

Organization for Economic Cooperation and Development (OECD). (2018). Making development co-operation work for Small Island Developing States: Highlights. https://www.oecd.org/dac/ financing-sustainable-development/development-finance-topics/ OECD-SIDS-2018-Highlights.pdf Accessed 22 June 2020.

Ruben, R., McDermott, J. \& Brouwer, I. (2020). Reshaping food systems after COVID-19. CGIAR Research Program on Agriculture for Nutrition and Health. http://a4nh.cgiar.org/2020/04/20/reshapingfood-systems-after-covid-19/?utm_source=feedburner\&utm medium $=$ feed\&utm_campaign $=\overline{\text { Feed }} \% 3 \mathrm{~A}+$ cgiar $-\mathrm{a} 4 \mathrm{nh}+\overline{\%}$ 28Agriculture + for + Nutrition+and + Health $\% 29$ Accessed 8 May 2020.

United Nations (UN). (2014). Report of the third international conference on small island developing states. http://www.un.org/ga/search/ view doc.asp?symbol=A/CONF.223/10\&Lang=E Accessed 8 May 2020.

World Bank. (2020). Data: World Bank country and lending groups, June 2019. Available online: https://datahelpdesk.worldbank.org/ knowledgebase/articles/906519-world-bank-country-and-lendinggroups Accessed 25 June 2020.

World Food Programme (2020). Caribbean COVID-19 Food Security \& Livelihoods Impact Survey. Regional Summary Report, April 2020. https://www.wfp.org/publications/caribbean-covid-19-foodsecurity-livelihoods-impact-survey Accessed 2 May 2020.

Wright, J. (2012). Sustainable agriculture and food security in an era of oil scarcity: Lessons from Cuba. Abingdon: Routledge.

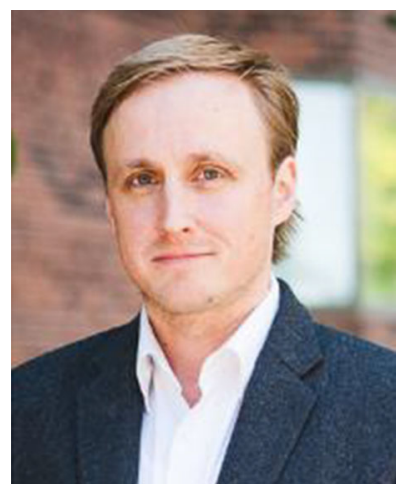

Gordon M. Hickey is an Associate Professor and William Dawson Scholar in the Department of Natural Resource Sciences at McGill University specializing in sustainable natural resource management, policy and governance. He is the Founding Head of the interdisciplinary Sustainable Futures Research Laboratory and an Associate Editor of the journals Food Security and Society \& Natural Resources. Prior to joining McGill, he worked in senior policy and management roles in government. He has been working on food security and sustainability issues in the Caribbean since 2010.

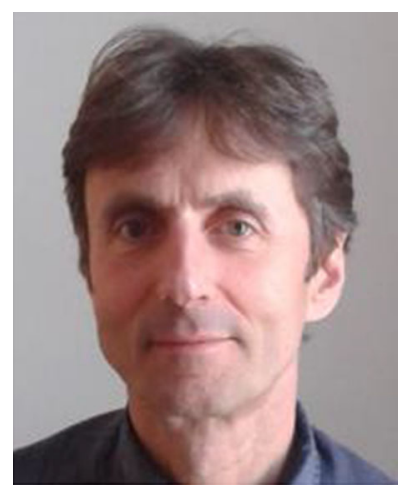

Nigel Unwin is a Director of Research in Global Public Health at the MRC Epidemiology Unit, University of Cambridge; a Professor of Diabetes at the European Centre for Environment and Human Health, University of Exeter; and an honorary Professor of Population Health Sciences at Caribbean Institute for Health Research, University of the West Indies (UWI). Between 2010 and 2016 he was a Professor in Public Health at UWI, based in Barbados. It was at UWI that he became interested in how food systems in the Caribbean are related to the high burdens of nutrition related diseases. He is currently collaborating on and leading research that aims to inform and evaluate interventions to improve nutrition in the Caribbean and Pacific. 